\title{
Knowledge on the Malaysian Food Heritage
}

\author{
Adilah Md Ramli, Mohd Salehuddin Mohd Zahari, \\ Nurhasmilaalisa Abdul Halim, Mohammed Haidrin Mohamed Aris \\ Universiti Teknologi MARA, Puncak Alam, 42300, Malaysia; \\ Universiti Putra Malaysia, Serdang, 43300, Malaysia; \\ Politeknik Sultan Idris Shah, Sungai Lang, 45100, Malaysia \\ m_adilah@hotmail.com
}

\begin{abstract}
Traditional food was closely associate with food heritage has become a significant role in the life of society. A study examines how far Malaysian knows about their food heritage identity. A total of 500 respondents located in Klang Valley participate in this study. Findings showed that food heritage been defined as traditional food. There is a significant relationship between genders with the definition of food heritage; the association of food heritage questions. The overall finding revealed that respondent understand the definition, the criteria's and type of traditional food associated with food heritage.

Keywords: Food Heritage; Identity; Knowledge

eISSN: 2398-4279 @ 2017. The Authors. Published for AMER ABRA by e-International Publishing House, Ltd., UK. This is an open access article under the CC BY-NC-ND license (http://creativecommons.org/licenses/by-ncnd/4.0/). Peer-review under responsibility of AMER (Association of Malaysian Environment-Behaviour Researchers), ABRA (Association of Behavioural Researchers on Asians) and cE-Bs (Centre for EnvironmentBehaviour Studies), Faculty of Architecture, Planning \& Surveying, UniversitiTeknologi MARA, Malaysia. https://doi.org/10.21834/ajqol.v2i5.9
\end{abstract}




\subsection{Introduction}

Food is signified as markers for identity regardless of geographical, social and political differences separating the populations. Takaki (2012) deduced that food identity ostensibly contributes to prosperity, international identification and reputation of a country and positive influence on the economy. Without common identity, a nation will have an ambiguous and conflicting identity due to lack of consensus which creates an adverse image and effects on the social integration within a country (Lin, Pearson, \& Cai, 2011). In many multi-cultural countries, to have a commonly accepted food identity to represent the image of a nation is important especially in term of tradition and authenticity. People are experiencing external pressures on their culture and tradition, including the threat of losing their food heritage or identity. In these gastronomic interactions, a region's heritage foods form a valuable 'blueprint' of its people, whereby food represents not only the physical need but also local culture and custom (Alonso \& Krajsic, 2013).Therefore, this study aim to investigate the knowledge of food heritage from the public (Malaysian) point of view to get some ideas of what Malaysian food heritage identity means to Malaysian on different gender

\subsection{Literature Review}

There are many factors like social, cultural, political and economic aspects influenced the formation of the national food identity. Similar to other countries such as Singapore (Henderson, 2014), Taiwan (Hui-tun, 2010), Vietnam (Avieli, 2013), Kenya (Mugalavai, Kiama, \& Omutimba, 2012), Swahili (Rolingher, 2009) and Croatia (Fox, 2007), Malaysia also experiences the necessity of having its food identity when sharing food, and cultural background are becoming a central issue in neighbouring countries. According to Chong (2012), each country is becoming more determined to defend and safeguard their cultural food as a heritage, as it forms the core identity of the country.

\subsection{Overview on food heritage}

Matta (2013) cited Bessiere and Tibere in defining food heritage as a set of material and immaterial elements of food cultures that have been considered as shared legacy or common good. This food heritage includes agricultural products, ingredients, dishes, techniques, recipes and food traditions. In Ramli, Zahari, Ishak, and Sharif (2013), food heritage has been clarified broadly by several researchers on the topics of food heritage which are related to the origin of the food products and food production of local produce. Wahid, Mohamed, and Sirat (2009) stated from former Commissioner of Heritage, Prof. Datuk Zuraina Majid categorized heritage foods in two categories. The first category refers to synonymous or common foods which are part of our lives, whereas the second consists of foods that face extinction, in other words, they were once part of our culture but are slowly dying out. 
Tibere and Aloysius (2013) comprises food heritage with rich cultural and historical value that belong to the societies, which can be traced from their food trails, for instance, the recipe used and technique of cooking. The rich cultural value creates a sense of 'belongingness' and helps to enhance people's pride that in turn could lead their willingness to conserve and preserve their cultural food heritage. Meanwhile, the historical facts provide knowledge of the past. This could be used as part of efforts to instill people's national ethos that brings 'togetherness' among the people. It would increase the level of understanding among the people especially those coming from a pluralistic country like Malaysia. The knowledge also helps them to learn and continue to negotiate their cultural differences.

There are great concerns and attention given to the preservation of traditional cuisine since it was closely related to the ingredients, preparation method, dishes and eating decorum. Cultural heritage is difficult to preserve and measure as it was associated with values, beliefs, behaviours, and rules of the society. The need for continuing and preserving heritage food is considered as a comparative advantage in maintaining local food culture in the face of homogenizing pressures from the outside (Shariff, Mokhtar, \& Zakaria, 2008) and continuation of preserving the creation of valued products especially the traditional cuisines (UNESCO, 2008).

\subsection{Methodology}

This study intends to explore the knowledge of food heritage identity between genders using the quantitative method to gather all necessary information.

\subsection{Sampling and population}

The information needed for this study was collected from 500 respondents in Klang Valley area using self-completed questionnaire survey. The target population was the public (Malaysian), consisting of major ethnic groups like Malay, Chinese and Indian. Malaysian citizens, consist of the ethnic group Bumiputera 67.4\% (Malay and other ethnic groups from Peninsular Malaysia and Malaysia East), Chinese $24.6 \%$, Indian $7.3 \%$ and others $0.7 \%$. The reason for choosing the three major ethnic groups because their foods are commonly accepted among Malaysians, hence, classified as Malaysian foods and qualified to be endorsed as heritage food (Bernama, 2012) and listed under the National Food Heritage (Negara, 2012).

Salkind (2003) argued that studying a sample rather than an entire population also leads to more reliable results, mainly because fatigue is reduced resulting in fewer errors in collecting data. Due to high population concentration, the sample of population was selected among Malaysian who resided in Klang Valley, which comprises of the Federal Territory of Kuala Lumpur, Putrajaya, the Petaling district in Selangor (Shah Alam, Petaling Jaya and Subang Jaya), Gombak, Klang and Hulu Langat and their suburbs and adjoining cities and towns (Valley, 2014). Respondents were selected based on their nationality (must 
be Malaysian) states upbringing, and they should be 30 years or older, and knowledgeable on to the subject matter (food heritage).

\subsection{Research Instrument}

The self-administered questionnaire was developed and adapted base on several variables derived from the framework of the conceptual study. The items in each dimension (independent and dependent variables) and scales used in the exploratory stage. The items in each dimension were adapted from previous studies (Guerrero et al., 2009; Hergesell, 2006; McDonald, 2011; Mohammad \& Chan, 2011; Trichopoulou, Soukara, \& Vasilopoulou, 2007). In this study, purposive sampling was employed to select the elements from the sample. It is a form of convenience sampling that researcher's judgment is used to select the sample elements (Hair, Money, Samouel, \& Page, 2007). A preliminary screening process was carried out to select suitable candidate/respondent. The screening process based on the criteria set by the researcher, to be precise respondent should be 30 years or older and is knowledgeable about food heritage. Respondents who fulfilled the required criteria could proceed with the questionnaire. Respondents have been briefed on the aims of the study before the questionnaire was handed to them. Collected data were analyzed using SPSS software. Statistical methods such frequencies and cross-tabulation using gender with all food heritage $(\mathrm{FH})$ questions items were used to address the objective of the study.

\subsection{Results and Discussions}

\subsection{Respondent profile}

Simple frequency and descriptive analysis were conducted on the respondent's demographic profile in Table 1. As reported in the table, the respondents were equal percentages for male and female. Regarding age group, more than half of the respondents were between $30-35(55 \%)$ years old and the least number of respondents aged $41-45$ (5.6\%). Based on ethnicity group, the majority were Malay $(76.8 \%)$ and the lowest percentage was the others (2.2\%) group, which comprised of Bumiputera: Sabah and Sarawak. In term of professions, the majority is in the private sector $(49.8 \%)$, and the lowest were students $(3 \%)$ and others $(4 \%)$, which comprised of housewives and pensioners. As for educational background, majorities were diploma holders $(61.2 \%)$ and the lowest were SRP leavers (4.4\%). 
Table 1: Demographic background

\begin{tabular}{llc}
\hline Demographic (N=500) & Frequency & $\begin{array}{c}\text { Percent } \\
(\%)\end{array}$ \\
\hline Gender & & \\
Male & 250 & 50.0 \\
Female & 250 & 50.0 \\
Age & & \\
30-35 & 275 & 55.0 \\
$36-40$ & 101 & 20.2 \\
$41-45$ & 28 & 5.6 \\
46-50 & 44 & 8.8 \\
51 and above & 52 & 10.4 \\
Ethnicity & & \\
Malay & 384 & 76.8 \\
Chinese & 58 & 11.6 \\
Indian & 47 & 9.4 \\
Others & 11 & 2.2 \\
Profession & & \\
Government & 190 & 38.0 \\
Private & 249 & 49.8 \\
Professional & 14 & 2.8 \\
Student & 15 & 3.0 \\
Other & 32 & 6.4 \\
& & \\
Education & & \\
UPSR & 4 & 0.8 \\
SRP/PMR & 22 & 4.4 \\
SPM & 129 & 25.8 \\
Diploma & 306 & 61.2 \\
Degree & 39 & 7.8 \\
\hline & & \\
\hline & &
\end{tabular}

\subsection{Definition of food heritage (FH)}

Table 2 shows majority respondent define of food heritage $(\mathrm{FH})$ as traditional food, with $20.6 \%$. FH has also been defined as food passed down from one generation to another with $13.9 \%$. Third most chosen FH definition are food related to the cultural background (i.e. ethnic background and culture) with $12.3 \%$. Fourth are original ingredients with original recipes with $11.9 \%$. In the fifth associated with celebration (i.e. festivals, religious celebrations and special occasions) with $11.6 \%$. Authentic cooking methods (e.g. prepared in a particular way, cooking style, and preparation) are in the six ranked with $10.9 \%$. Sensory properties of food (i.e. taste, aroma, and texture) are the second lowest with $10.5 \%$, and lastly common or daily food are chosen only for $8.2 \%$. Both genders showed the significant $(p<.05)$ with all the definition except for traditional food, $p$-value $=0.876(p>$ .05) showing there is none significant differences between the genders in selecting traditional food as FH definition. 


\begin{tabular}{llll}
\multicolumn{4}{c}{ Table 2: Gender * $\mathrm{Q} 4$} \\
\hline \multirow{2}{*}{$(\mathrm{N}=500)$} & $\begin{array}{l}\text { Overall } \\
(\%)\end{array}$ & P-value \\
\hline $\mathrm{Q} 4$ & Traditional Food & 20.6 & 0.876 \\
& Food Passed Down & 13.9 & $0.006^{*}$ \\
& Related to cultural background & 12.3 & $0.000^{*}$ \\
& Original Ingredients & 11.9 & $0.000^{*}$ \\
& Celebration & 11.6 & $0.000^{*}$ \\
& Authentic Cooking Method & 10.9 & $0.000^{*}$ \\
& Sensory Properties & 10.5 & $0.000^{*}$ \\
& Common or Daily Food & 8.2 & $0.000^{*}$ \\
\hline
\end{tabular}

${ }^{*} p<0.05$ (2-sided)

The preferences of traditional foods as the leading definition of $\mathrm{FH}$ and its relationship to food transferred from one generation to another been supported by the previous researcher stated that traditional food as part of culture, identity, and heritage of countries all around the world. It is also as a means of usage in the community for a period, showing the transmission between generations (Hamzah et al., 2015; Sharif, Zahari, Nor, \& Muhammad, 2013). It also linked with celebration and related to a special occasion (Vitterso \& Amilien, 2011). Although food that are common or daily is less considerate by respondent in this study, it can be defined as FH in the terms of the set of material and immaterial elements of food cultures that are considered as shared legacy or a common product (Ishak, Zahari, \& Othman, 2013; Matta, 2013).

\subsection{List of Favorite Traditional Food And Drinks Considered As Food Heritage (FH)}

Table 3 and 4 listed food that most frequent mention by the respondent that been endorsed as National Food Heritage (NFH) (Negara, 2012). Findings revealed that cakes, porridge \& dessert categories are the most frequent mention by the male $(50.9 \%)$ and female $(49.1 \%)$ and stated three most favourite traditional foods such as Bubur Cha Cha, Kuih Seri Muka and Karipap. Second most frequent mention is the rice-based category with male (53.5\%) and female (46.5\%); they identified Nasi Lemak, Nasi Kerabu, Nasi Dagang as traditional food considered as FH. Thirdly, is gravies and accompaniments category with Rendang, Masak Asam Pedas and Budu been identified under this category with $51.7 \%$ are male, and $48.3 \%$ are female. Noodles categories such as Laksa, Mee Kari, Laksa Johor frequently mention by female $(50.3 \%)$ and male $(49.7 \%)$ in the fourth rank. In fifth place, drink category such as Teh Tarik, Cendol and Air Batu Campur (ABC) mostly mentions by male (53.4\%) and female (46.6\%). The last category is an appetizer with top three mentions are Kerabu Mangga Muda, Sambal Belacan and Cencaluk, from female (54.5\%) and male $(45.5 \%)$. As mention in table 3 , most of the food categories, show male mostly mention food categories such as cakes, porridge and dessert, rice base, gravies and accompaniments and drinks. Meanwhile, female mention more toward noodles and appetiser categories. Overall both genders do acknowledge NFH list as their favourite food. 
Table 3: Traditional food by categories

\begin{tabular}{lllll}
\hline \multicolumn{2}{l}{ Categories } & $\begin{array}{l}\text { Frequency } \\
(\mathrm{N}=500)\end{array}$ & $\begin{array}{l}\text { Overall }(\%) \\
\text { Female }\end{array}$ & Male \\
\hline Q5 & Cakes, Porridge \& Dessert & 493 & 49.1 & 50.9 \\
& Rice based & 301 & 46.5 & 53.5 \\
Gravies \& Accompaniments & 240 & 48.3 & 51.7 \\
Noodles & 151 & 50.3 & 49.7 \\
Drinks & 178 & 46.6 & 53.4 \\
Appetiser & 112 & 54.5 & 45.5 \\
\hline
\end{tabular}

Table 4: Most frequent mention traditional food and drinks in each category

\begin{tabular}{|c|c|c|}
\hline Category & Top 3 traditional food & $(\%)$ \\
\hline & & 21.6 \\
\hline \multirow[t]{3}{*}{ Rice Based } & Nasi Lemak & 9.8 \\
\hline & Nasi Kerabu & 9.0 \\
\hline & Nasi Dagang & \\
\hline \multirow[t]{3}{*}{ Noodles } & Laksa & 35.1 \\
\hline & Mee Kari & 29.1 \\
\hline & Mee Mamak & 9.9 \\
\hline \multicolumn{3}{|l|}{ Gravies \& } \\
\hline Accompaniments & Rendang & 41.3 \\
\hline \multirow[t]{2}{*}{ Dishes } & Masak Asam Pedas & 10.8 \\
\hline & Budu & 9.6 \\
\hline \multirow[t]{3}{*}{ Appetiser } & Kerabu Mangga Muda & 27.7 \\
\hline & Sambal Belacan & 23.2 \\
\hline & Cencaluk & 12.5 \\
\hline \multirow{9}{*}{$\begin{array}{l}\text { Cake, Porridges } \\
\& \text { Dessert }\end{array}$} & Bubur cha cha & 10.5 \\
\hline & Bubur kacang hijau & 9.3 \\
\hline & Pengat & 4.3 \\
\hline & Kuih seri muka & 8.1 \\
\hline & Kuih koci & 4.7 \\
\hline & Kuih keria & 2.6 \\
\hline & Karipap & 5.5 \\
\hline & Agar-agar & 4.7 \\
\hline & Bahulu & 4.7 \\
\hline \multirow[t]{3}{*}{ Drinks } & Teh tarik & 35.4 \\
\hline & Cendol & 27.5 \\
\hline & $A B C$ & 20.2 \\
\hline
\end{tabular}


The traditional foods and drink mention are popular among respondent as this food are enjoyed by all religions and races in Malaysia (Abdullatib, 2009; Md Nor et al., 2012). Former Heritage Commissioner reveals that heritage dishes were chosen based either it is synonymous with Malaysia or almost extinct, and NFH is meant to popularize Malaysia's food worldwide and create greater awareness of the country's heritage (Wo, 2009) and the differences in the way they categorized food can be linked to their identity (Bugge, 2010).

\subsection{Food Heritage (FH) associated with...}

In Table 5 showed that most of the responded associated $\mathrm{FH}$ with preservation of authentic traditional food for $30.1 \%$. Second-ranked, representing the image of the country at $27 \%$. The third rank has been associated with representing food identity of the country with $22.5 \%$. Sustainability of traditional food is considered only for $20.4 \%$ is the less associated with $\mathrm{FH}$.

\begin{tabular}{|c|c|c|c|}
\hline & $N=500$ & $\begin{array}{l}\text { Overall } \\
(\%)\end{array}$ & P-value \\
\hline \multirow[t]{4}{*}{ Q8 } & Preservation & 30.1 & 0.079 \\
\hline & Represent Image & 27.0 & $0.010^{*}$ \\
\hline & Food Identity & 22.5 & $0.002^{*}$ \\
\hline & Sustainability & 20.4 & $0.000^{*}$ \\
\hline
\end{tabular}

As shown in Table 5, only the preservation of authentic traditional food showed no significant $p=0.079(p>.05)$ between the genders. FH need to be preserved and sustain as its represented country image and identity as some dishes been endowed with iconic status and worthy to celebrate and to safeguard it (Henderson, 2014). Hence, it is important for every ethnic to preserve their food practiced by the young generations to retain their ethnic identity (Md Nor et al., 2012).

\subsection{Criteria of food heritage}

As shown in Table 6 , criteria of food heritage $(\mathrm{FH})$ revealed that respondent views traditional value as most important with $12.1 \%$. Second criteria are originality with $11.8 \%$. Third criteria of $\mathrm{FH}$ are authentic flavor with $10.5 \%$ and the three lowest percentages, criteria been chosen are technology (3.9\%), convenience (3.9\%); and commonalities (3.8\%). A comparison of genders with criteria of $\mathrm{FH}$ only traditional value, historical value, food presentation and cross culturing showing not significant ( $p>.05)$. Its shows that there are no differences view between the genders on the criteria's. 
FH criteria's been indicated by Tibere and Aloysius (2013) as comprises of two significant elements: rich cultural value and historical insights that belong to the societies, which can be traced from their food trails, for instance, the recipe used and technique of cooking. $\mathrm{FH}$ criteria's such as commonalities relate by Abdullatib (2009) as food that been enjoyed by every religions and ethnicity in Malaysia. The preparation skills are not limited to one race only. The criteria such as "heritage, traditional and local" food are enquired by tourist as they pursuit for authenticity (Sims, 2009).

Table 6: GenderQ9

\begin{tabular}{llll}
\hline & & $\begin{array}{l}\text { Overall } \\
(\%)\end{array}$ & P-value \\
\hline Q9 & Traditional value & 12.1 & 0.807 \\
& Originality & 11.8 & $0.000^{*}$ \\
& Authentic flavour & 10.5 & $0.005^{*}$ \\
& Historical value & 9.8 & 0.161 \\
& Cooking method & 9.0 & $0.000^{*}$ \\
& Staple food ingredients & 7.0 & $0.009^{*}$ \\
& Sensory properties & 6.8 & $0.000^{*}$ \\
& Food presentation & 6.3 & 0.067 \\
& Variety & 5.3 & $0.001^{*}$ \\
& Cross-culturing & 5.2 & $0.054^{*}$ \\
& Food Innovation & 4.5 & $0.000^{*}$ \\
& Technology & 3.9 & $0.000^{*}$ \\
& Convenience & 3.9 & $0.000^{*}$ \\
& Commonalities & 3.8 & $0.000^{*}$ \\
\hline * $\mathrm{p}<0.05(2-$ sided $)$ & &
\end{tabular}

\subsection{Conclusion}

The overall study on knowledge of food heritage established interesting finding between gender especially the definition of $\mathrm{FH}$ as traditional food, food been transferred to generations and related to individual or society cultural background but less recognize as common or daily food although in the past literature stated that food can be common regardless ethnicity and belief of the individual or society. FH knowledge also best shown in describing the traditional food as FH whereby it can be seen the differences in the tendency of choosing or acknowledge the traditional food in Table 3 and 4 show female tendency to relate traditional foods with $\mathrm{FH}$ in noodles and appetizers category more than men. The $\mathrm{FH}$ represented more toward preservation of authentic traditional food in both genders as it feels the importance preserve $\mathrm{FH}$ as an icon and unique to the country more than represent an image, identity, and sustainability for younger generations. It also shows FH criteria's in 
both genders chosen traditional value as it sees the cultural history of the food is an important criterion in $\mathrm{FH}$. In overall, $\mathrm{FH}$ is fully understood by the public. $\mathrm{FH}$ were less regard as common or daily food, and these made the research to ponder why this occurred as most literature stated traditional food coming from common and daily food and suggested more issues to be explored.

This study contributes the current literature to the public knowledge towards food heritage identity. It also can be used as a measurement tool for the Department of Heritage in developing a new way to impart knowledge of National Food Heritage to the public. In the future, research on different states in Malaysia could result in many interesting findings. The results are shown in the study only encircled the gender category that may not reflect the whole demographic background. It may suggest using others variables such as age, education background and ethnicity to make more informative findings

\section{References}

Abdullatib, S. (2009). 100 Makanan Tradisi, Kosmo Online. Retrieved from http://kosmo.com.my/kosmo

Alonso, A. D., \& Krajsic, V. (2013). Food heritage down under: olive growers as Mediterranean 'food ambassadors'. Journal of Heritage Tourism, 8(2-3), 158-171.

Avieli, N. (2013). What is 'Local Food?'Dynamic culinary heritage in the World Heritage Site of Hoi An, Vietnam. Journal of Heritage Tourism, 8(2-3), 120-132.

Bedi, R. S. (2012). Not quite over the tossing, thestar. Retrieved from http://thestar.com.my

Bernama. (2012). 154 Butiran Diisytihar Sebagai Warisan Kebangsaan, Bernama. Retrieved from www.bernama.com

Bugge, A. B. (2010). Young people's school food styles: Naughty or nice? Young, 18(2), 223-243.

Chaney, S., \& Ryan, C. (2012). Analyzing the evolution of Singapore's World Gourmet Summit: An example of gastronomic tourism. International Journal of Hospitality Management, 31, 309-318.

Chong, J. W. (2012). " Mine, Yours or Ours?": The Indonesia-Malaysia Disputes over Shared Cultural Heritage. SOJOURN: Journal of Social Issues in Southeast Asia, 27(1), 1-53.

DeSoucey, M. (2010). Gastronationalism: Food Traditions and Authenticity Politics in the European Union. American Sociological Review, 75(3), 432-455.

Fox, R. (2007). Reinventing the gastronomic identity of Croatian tourist destinations. International Journal of Hospitality Management, 26(3), 546-559.

Guerrero, L., Guardia, M. D., Xicola, J., Verbeke, W., Vanhonacker, F., Zakowska-Biemans, S., Hersleth, M. (2009). Consumer-driven defination of traditional food products and innovation in traditional foods. A qualitative cross-cultural study. Appetite, 52. 
Hair, J. F., Money, A. H., Samouel, P., \& Page, M. (2007). Research Methods for Business. USA: John Wiley \& Sons Itd.

Hamzah, H., Karim, M. S. A., Othman, M., Hamzah, A., \& Muhammad, N. H. (2015). Challenges in Sustaining the Malay Traditional Kuih among Youth. International of Social Science and Humanity, 5(5), 472-478.

Henderson, J. C. (2014). Food and culture: in search of a Singapore cuisine. British Food Journal, 116(6), 904917.

Hergesell, A. (2006). Influence of the World Heritage Certification on Destination Choice. (Master of Arts), Bournemouth University.

Hui-tun, C. (2010). Fabricating Authentic National Cuisine Identity and Culinary Practice in Taiwan. New School University, United States New York. Retrieved from http://search.proquest.com.

Ishak, N., Zahari, M. S. M., \& Othman, Z. (2013). Influence of Acculturation on Foodways among Ethnic Groups and Common Acceptable Food. Procedia-Social and Behavioral Sciences, 105, 438-444.

Lim, Y. (2012). KL central cultural makeover, The Star online. Retrieved from http://thestar.com.my

Lin, Y.-C., Pearson, T. E., \& Cai, L. A. (2011). Food as a form of destination identity: A tourism destination brand perspective. Tourism and Hospitality Research, 11(1), 30-48.

Malaysia, D. o. S. (2011). Population Distribution and Basic Demographic Characteristic Report 2010 (D. o. S. Malaysia, Trans.): Department of Statistic Malaysia.

Matta, R. (2013). Valuing Native Eating: The Modern Roots of Peruvian Food Heritage. Anthropology of food, S8.

McDonald, H. (2011). Understanding the antecedents to public interest and engagement with heritage. European journal of Marketing, 45(5), 780-804.

Md Nor, N., Sharif, M. S. M., Zahari, M. S. M., Salleh, H. M., Isha, N., \& Muhammad, R. (2012). The Transmission Modes of Malay Traditional Food Knowledge within Generations. Procedia - Social and Behavioral Sciences, 50(0), 79-88.

Mohammad, T., \& Chan, J. K. L. (2011). Authenticity Representation of Malay Kelantan Ethnic Cuisine. Paper presented at the The 2nd International Research Symposium in Service Management, Yogyakarta, INDONESIA.

Mugalavai, V. K., Kiama, M. F. W., \& Omutimba, H. N. (2012). Using Traditional Cuisine Contexts as a Channel for Inter-Ethnic Social Integration in Kenya. International Journal of Social Science Tomorrow, 1(2).

Negara, J. W. (2012). Perisytiharan Warisan Kebangsaan. In J. W. Negara (Ed.), Kementerian Penerangan Komunikasi dan Kebudayaan (pp. 19). Malaysia: Jabatan Warisan Negara.

Ramli, A., Zahari, M. M., Ishak, N., \& Sharif, M. M. (2013). Food heritage and nation food identity formation. Hospitality and Tourism: Synergizing Creativity and Innovation in Research, 407.

Rolingher, L. (2009). Edible identities: Food, cultural mixing and the making of identities on the Swahili Coast. University of Alberta.

Salkind, N. J. (2003). Exploring Research United States of America: Prentice Hall. 
Sharif, M. S. M., Zahari, M. S. M., Nor, N. M., \& Muhammad, R. (2013). Factors that Restrict Young Generation to Practice Malay Traditional Festive Foods. Procedia-Social and Behavioral Sciences, 101, 239-247.

Shariff, N. M., Mokhtar, K., \& Zakaria, Z. (2008). Issues in the Preservation of Traditional Cuisines: A Case Study in Northern Malaysia. International Journal of the Humanities, 6(6), 101-106

Sims, R. (2009). Food, place and authenticity: local food and the sustainable tourism experience. Journal of Sustainable Tourism, 17(3), 321-336.

Takaki, R. (2012). Strangers from a different shore: A history of Asian Americans (updated and revised): eBooklt. com.

Tibere, L., \& Aloysius, M. (2013). Malaysia as a Food-Haven Destination: The Vision and its Sustainability. AsiaPacific Journal of Innovation in Hospitality and Tourism, 2(1), 37-51

Trichopoulou, A., Soukara, S., \& Vasilopoulou, E. (2007). Traditional foods: a science and society perspective. Trends in Food Science \& Technology, 18(8), 420-427.

UNESCO. (2008). World Heritage Information Kit. France: UNESCO World Heritage Center Retrieved from http://whc.unesco.org.

Valley, G. K. L. K. (2014). Greater KL/KV comprises 10 local authorities. Retrieved 28 Dec 2014, 2014, from http://app.kwpkb.gov.my

Vitterso, G., \& Amilien, V. (2011). From tourist product to ordinary food? Anthropology of food, 8. Retrieved from Anthropology of food website: http://aof.revues.org/6833

Wahid, N. A., Mohamed, B., \& Sirat, M. (2009). Heritage food tourism: bahulu attracts? Paper presented at the Proceedings of 2nd National Symposium on Tourism Research, Universiti Sains Malaysia, Penang, Malaysia 18 July 2009. Theories and Applications.

Wo, C. T. (2009). Dish branding, thestar. Retrieved from http://thestar.com.my. 